\title{
Simultaneous quantification of depolymerization and mineralization rates by a novel ${ }^{15} \mathrm{~N}$ tracing model
}

\author{
Louise C. Andresen ${ }^{1}$, Anna-Karin Björsne ${ }^{1}$, Samuel Bodé ${ }^{2}$, Leif Klemedtsson ${ }^{1}$, Pascal Boeckx ${ }^{2}$, and \\ Tobias Rütting ${ }^{1}$ \\ ${ }^{1}$ Department of Earth Sciences, University of Gothenburg, 40530 Gothenburg, Sweden \\ ${ }^{2}$ Isotope Bioscience Laboratory, ISOFYS, Ghent University, 9000 Ghent, Belgium
}

Correspondence to: Louise C. Andresen (louise.andresen@gu.se)

Received: 9 February 2016 - Published in SOIL Discuss.: 3 March 2016

Accepted: 25 August 2016 - Published: 6 September 2016

\begin{abstract}
The depolymerization of soil organic matter, such as proteins and (oligo-)peptides, into monomers (e.g. amino acids) is currently considered to be the rate-limiting step for nitrogen (N) availability in terrestrial ecosystems. The mineralization of free amino acids (FAAs), liberated by the depolymerization of peptides, is an important fraction of the total mineralization of organic N. Hence, the accurate assessment of peptide depolymerization and FAA mineralization rates is important in order to gain a better process-based understanding of the soil $\mathrm{N}$ cycle. In this paper, we present an extended numerical ${ }^{15} \mathrm{~N}$ tracing model Ntrace, which incorporates the FAA pool and related $\mathrm{N}$ processes in order to provide a more robust and simultaneous quantification of depolymerization and gross mineralization rates of FAAs and soil organic N. We discuss analytical and numerical approaches for two forest soils, suggest improvements of the experimental work for future studies, and conclude that (i) when about half of all depolymerized peptide $\mathrm{N}$ is directly mineralized, FAA mineralization can be as important a rate-limiting step for total gross $\mathrm{N}$ mineralization as peptide depolymerization rate; (ii) gross FAA mineralization and FAA immobilization rates can be used to develop FAA use efficiency (NUEFAA), which can reveal microbial $\mathrm{N}$ or carbon $(\mathrm{C})$ limitation.
\end{abstract}

\section{Introduction}

Soil organic nitrogen (SON) mineralization is essentially a sequence of depolymerization of polymeric organic compounds followed by the mineralization of the liberated monomers (Schimel and Bennett, 2004). Inorganic nitrogen (IN), such as nitrate $\left(\mathrm{NO}_{3}^{-}\right)$and ammonium $\left(\mathrm{NH}_{4}^{+}\right)$, as well as free amino acids (FAAs) are known to be the main plant N sources (Schimel and Chapin III, 1996; Bardgett et al., 2003). Therefore, it is essential to know more about the production of mineral and amino acid $\mathrm{N}$, and the balance between mineralization and immobilization of $\mathrm{N}$, in order to have a better understanding of $\mathrm{N}$ availability. Gross $\mathrm{N}$ mineralization includes the mineralization of FAAs and the mineralization of other organic monomers and potentially also includes a share of $\mathrm{NH}_{4}^{+}$released from mineral complexes (Houlton and Morford, 2015). It has been estimated across grassland, cropland, and heathland ecosystems that FAA mineralization can be a substantial fraction of the $\mathrm{N}$ mineralization (34 to $88 \%$; reviewed in Andresen et al., 2015). Hence, amino acid mineralization is important for IN availability; hence, our research question is whether the peptide depolymerization and FAA mineralization rates are two equally important steps co-limiting for $\mathrm{N}$ availability.

Carbon or $\mathrm{N}$ limitation of microbes in a soil governs the direction of the soil $\mathrm{N}$ flow towards mineralization $(\mathrm{N}$ in excess) or immobilization (C in excess) (Robertson and Groffman, 2015). The soil C-to-N ratio is a rather blunt measure for the C-to-N ratio of microbe-used substrates as it potentially camouflages inert mineral components or recalcitrant soil organic matter. Instead, Schimel and Bennett (2004) suggested depolymerization rates, driven by extracellular enzymatic activity, as the rate-limiting step for the terrestrial $\mathrm{N}$ cycle. Thereby, depolymerization rates would also determine the availability of the amino acid substrate within the soil and 
assess the $\mathrm{N}$ release from the biologically available fraction in the soil. Following this, Wanek et al. (2010) provided a methodological development of ${ }^{15} \mathrm{~N}$ pool dilution assays to determine gross peptide depolymerization rates, and by combining this with ${ }^{15} \mathrm{~N}$ tracing, the quantification of gross FAA mineralization can also be achieved (Andresen et al., 2015). These approaches apply analytical calculations (Kirkham and Bartholomew, 1954; Watkins and Barraclough, 1996), handling one flux at a time, which has some limitations: (1) the analytical solutions only provide total consumption and production rates and not the specific processes, (2) analytical solutions only consider zero-order kinetics, (3) the possibility of remineralization or remobilization limits the experimental work to short time steps, and finally (4) with the analytical approach gross rates are sequentially quantified, which does not take into consideration possible interactions; hence, the numerical modelling provides a more coherent framework as the process rates are quantified simultaneously (Rütting et al., 2011). To advance our understanding of the organic $\mathrm{N}$ dynamics and mineralization, we deemed it timely to present a novel numerical ${ }^{15} \mathrm{~N}$ tracing model. Given the obtained amino acid immobilization and amino acid mineralization rates, the FAA use efficiency (NUE $\mathrm{FAA}_{\text {) }}$ can indicate whether a $\mathrm{C}$ or $\mathrm{N}$ limitation is occurring.

In this paper we combine two parallel ${ }^{15} \mathrm{~N}$ tracing experiments, in which soil is separately amended with ${ }^{15} \mathrm{~N}$ labelled ammonium or an amino acid mixture. By splitting the amino-acid-labelled incubation, two rates (the depolymerization rate and the amino acid mineralization rate) were assessed from one label. For data analysis, we further developed the numerical ${ }^{15} \mathrm{~N}$ tracing model Ntrace (Müller et al., 2007) to explicitly account for FAA turnover, in order to simultaneously quantify gross peptide depolymerization, gross FAA mineralization, and total gross $\mathrm{N}$ mineralization in forest soils. For our selected mineral soils from Swedish spruce forest, our hypotheses are (1) that FAA mineralization is a major, important part of gross $\mathrm{N}$ mineralization and that 2) due to year-long forestry in this area, we expect the soil to be carbon limited rather than $\mathrm{N}$ limited.

\section{Methods}

\subsection{Field site}

Soil was sampled from two forests at the Skogaryd Research Catchment part of SITES (Swedish Infrastructure for Ecosystem Studies, http://www.fieldsites.se), situated in southwest Sweden $\left(58^{\circ} 23^{\prime} \mathrm{N}, 12^{\circ} 09^{\prime} \mathrm{E} ; 60 \mathrm{~m}\right.$ a.s.l. - above sea level). Mean annual temperature is $6.4^{\circ} \mathrm{C}$, and the mean annual precipitation is $709 \mathrm{~mm}$ (Ernfors et al., 2011). The soil of the first forest was an Umbrisol with a sandy loam texture and was planted with Norway spruce (Picea abies) in the 1950s. The vegetation was classified as a spruce forest of the low-herb type based on the classification system by Påhlsson (1998), with sparse ground vegetation dominated by bryophytes (Mnium hornum, Polytricum formosum, and Pleurozium schreberi). The second forest was on a Podzol soil, where the vegetation was classified as a spruce forest of the bilberry type (Påhlsson, 1998). The tree stand (Norway spruce) was 55-130 years old and $23-30 \mathrm{~m}$ high. The ground vegetation was dominated by Vaccinium myrtillus and mosses.

\subsection{Soil sampling}

Soil was sampled with an auger on 14 April 2014 (Umbrisol) and 12 May 2014 (Podzol), each with five field replicates. The air temperature at both sampling times was $11^{\circ} \mathrm{C}$. For the Umbrisol, the thin litter layer and vegetation was pushed aside and the soil was sampled as far as $10 \mathrm{~cm}$ depth. For the Podzol, the soil was sampled below the $\mathrm{O}$ horizon and $10 \mathrm{~cm}$ down. These depths were selected to get matching low soil organic matter (SOM) contents. The soil was immediately transported to the lab, where roots and stones were manually removed. Wet soil $(40 \mathrm{~g})$ was placed in $250 \mathrm{~mL}$ glass bottles with a lid with a small hole and pre-incubated for a week at a constant temperature $\left(20^{\circ} \mathrm{C}\right)$ prior to labelling with ${ }^{15} \mathrm{~N}$.

\section{$2.3{ }^{15} \mathrm{~N}$ labelling incubations}

The pre-incubated soil was labelled with ${ }^{15} \mathrm{~N}$ in two different treatments, either receiving $\left({ }^{15} \mathrm{NH}_{4}\right)_{2} \mathrm{SO}_{4}\left(99 \%{ }^{15} \mathrm{~N}\right)$ or ${ }^{15} \mathrm{~N}$-amino-acid mixture ("cell-free" amino acid mix, $20 \mathrm{AA}$, U- ${ }^{15} \mathrm{~N}$ 96-98\%, chemical purity $>98 \%$; Cambridge Isotope Laboratories, USA). The total $\mathrm{N}$ addition with $\mathrm{NH}_{4}^{+}$ was $0.6 \mu \mathrm{g} \mathrm{N} \mathrm{g}^{-1}$ dry soil. The total added amino acids (AAs) were $9.32 \mu \mathrm{g} \mathrm{N} \mathrm{g}^{-1}$ dry soil (Umbrisol) or $7.72 \mu \mathrm{g} \mathrm{N} \mathrm{g}^{-1}$ dry soil (Podzol). The label solution was added to the preincubated soil using a pipette $(4 \mathrm{~mL}$ per bottle) and quickly stirred with a clean spatula.

Soils from $\mathrm{NH}_{4}^{+}$labelling were extracted using a $1: 2$ soilto-liquid ratio, with $1 \mathrm{M} \mathrm{KCl}$, by shaking for $1 \mathrm{~h}$ at $120 \mathrm{rpm}$, then the samples were filtered (Whatman qualitative filter papers, no. 1) and kept frozen $\left(-18^{\circ} \mathrm{C}\right)$ until further processing. Soil extractions were done on one set of samples directly after labelling $(13 \mathrm{~min})$; the rest of the bottles were incubated in a dark room at a constant temperature $\left(20^{\circ} \mathrm{C}\right)$ until extraction after 24, 48, 96, 168, and $240 \mathrm{~h}$ (hours).

Soils from AA labelling were divided in two parts immediately after label addition, prior to incubation in the dark room. Simultaneously one half was extracted with $1 \mathrm{M} \mathrm{KCl}$ as described above, and the other half was extracted with $10 \mathrm{mM} \mathrm{CaSO}_{4}$ containing $3.4 \%$ formaldehyde in $1: 2$ soilto-liquid ratio by shaking for $1 \mathrm{~h}$ at $120 \mathrm{rpm}$; then the samples were filtered (Whatman qualitative filter papers, no. 1) and kept frozen until further processing. Extractions were done $13 \mathrm{~min}$ and $0.5,1,2$, and $6 \mathrm{~h}$ after labelling. The $\mathrm{CaSO}_{4}$ was selected because deionized water alone lyses microbial cells, thereby releasing a large flux of amino acids from the cells. Formaldehyde was used in order to inhibit microbial con- 
sumption or activity during the shaking time. The $\mathrm{KCl}$ extract was made for ${ }^{15} \mathrm{~N}-\mathrm{NH}_{4}$ analyses.

(a)

\subsection{Analysis of ${ }^{15} \mathrm{~N}$}

All $\mathrm{KCl}$ extracts were prepared for the analysis of ${ }^{15} \mathrm{~N}$ contents of $\mathrm{NH}_{4}^{+}$by chemical conversion to $\mathrm{N}_{2} \mathrm{O}$ and analysed by isotope ratio mass spectrometry (IRMS) (ANCATGII (automated nitrogen carbon analyser - trace gas II) interfaced with a 20-20 IRMS, SerCon, UK) as described by Stevens and Laughlin (1994). $\mathrm{NH}_{4}^{+}$concentration was measured using a flow injection analyzer (Auto Analyzer 3, Bran + Luebbe, Norderstedt, Germany).

The $\mathrm{CaSO}_{4}$ extracts for ${ }^{15} \mathrm{~N}-\mathrm{AA}$ analysis were purified using cation-exchange cartridges (OnGuard II H, $1 \mathrm{cc}$, Dionex), conditioned with ultrapure water (>18.2 M $\Omega$ ), $3 \mathrm{M}$ $\mathrm{NH}_{3}$, and $1 \mathrm{M} \mathrm{HCl}$. After loading the extract on the cationexchange resin, the cartridge was washed with $10 \mathrm{~mL}$ ultra-

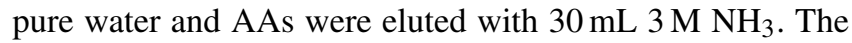
purified sample was dried under reduced pressure at $35^{\circ} \mathrm{C}$ and finally derivatized using ethanol pyridine and ethyl chloroformate (Wanek et al., 2010; Husek, 1991). Finally, the individual FAAs were measured by gas chromatography-mass spectrometry (GC-MS, Trace GC - DSQ, Thermo Fisher). Separation was done on a OV1701 column $(30 \mathrm{~m} \times 0.25 \mathrm{~mm}$ ID $\times 0.25 \mu \mathrm{m}$ film; Sigma-Aldrich, Diegem, Belgium) for the following 16 amino acids: alanine (Ala $m / z: 116 / 117$ ), glycine (Gly $m / z$ : 102/103), valine (Val m/z: 144/145), leucine and isoleucine (Leu and Ile $m / z$ : 158/159), serine (Ser $m / z: 131 / 132$ ), threonine (Thr $m / z: 146 / 147$ ), proline (Pro $m / z: 142 / 143$ ), aspartic acid (Asp m/z: 188/189), asparagine (Asn $m / z$ : 141/143), methionine (Met $m / z$ : 249/250), glutamic acid (Glu m/z: 202/203), phenylalanine (Phe $m / z:$ 192/193), lysine (Lys $m / z: 156 / 157$ ), tyrosine (Tyr $m / z: 280 / 281$ ), and tryptophan (Trp $m / z: 130 / 131)$. It was not possible to measure the following amino acids: arginine, glutamine, histidine, and cysteine.

\subsection{Soil properties}

Soil water content was determined gravimetrically (gravimetric soil water content - GWC) by oven drying of $\sim 10 \mathrm{~g}$ soil samples to a constant weight at $75^{\circ} \mathrm{C}$. Soil $\mathrm{pH}$ was measured in $1 \mathrm{M} \mathrm{KCl}$ extracts. Soil organic matter was determined on $2 \mathrm{~g}$ of dried soil samples by loss of ignition $\left(8 \mathrm{~h}\right.$ at $\left.500^{\circ} \mathrm{C}\right)$. Total soil $\mathrm{N}$ and $\mathrm{C}$ content was determined on ground soil with an elemental analyzer (ANCA SerCon, Crew, UK).

\subsection{Calculations}

\subsubsection{Analytical equations}

In order to quantify the gross $\mathrm{N}$ mineralization $(M), \mathrm{NH}_{4}^{+}$ consumption $\left(C_{\mathrm{NH}_{4}}\right)$, FAA consumption $\left(C_{\mathrm{FAA}}\right)$, and peptide
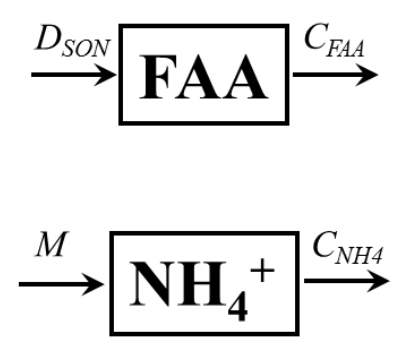

(b)

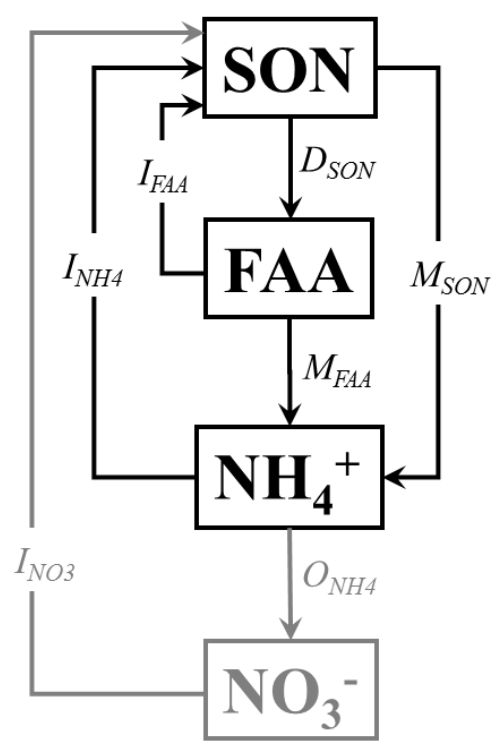

Figure 1. (a) Schematic analytical model: gross $\mathrm{N}$ mineralization $(M)$; ammonium consumption $\left(C_{\mathrm{NH}_{4}}\right)$; amino acid consumption $\left(C_{\mathrm{FAA}}\right)$ and peptide depolymerization rate $\left(D_{\mathrm{SON}}\right)$. (b) The conceptual model Ntrace considers pools for soil organic nitrogen (SON), free amino acid (FAA), ammonium $\left(\mathrm{NH}_{4}^{+}\right.$), and nitrate $\left(\mathrm{NO}_{3}^{-}\right)$and for fluxes of peptide depolymerization rate $\left(D_{\mathrm{SON}}\right)$, FAA mineralization rate $\left(M_{\mathrm{FAA}}\right)$, FAA immobilization rate $\left(I_{\mathrm{FAA}}\right)$, mineralization rate of organic $\mathrm{N}\left(M_{\mathrm{SON}}\right)$, immobilization rate of $\mathrm{NH}_{4}^{+}\left(I_{\mathrm{NH}_{4}}\right), \mathrm{NH}_{4}^{+}$oxidation rate $\left(O_{\mathrm{NH}_{4}}\right)$, and $\mathrm{NO}_{3}^{-}$immobilization rate $\left(I_{\mathrm{NO}_{3}}\right)$. Grey pools and fluxes could not be investigated in the current study due to too low a nitrate content.

depolymerization rates $\left(D_{\mathrm{SON}}\right.$; Fig. 1$)$, the analytical equations developed for isotope pool dilution experiments were used (Kirkham and Bartholomew, 1954):

For $p>c$

$$
\begin{aligned}
& p=\frac{M_{t}-M_{0}}{t} \times \frac{\ln \left(H_{0} M_{t} / H_{t} M_{0}\right)}{\ln \left(M_{t} / M_{0}\right)}, \\
& c=\frac{M_{t}-M_{0}}{t} \times \frac{\ln \left(H_{0} / H_{t}\right)}{\ln \left(M_{t} / M_{0}\right)} .
\end{aligned}
$$


For $p=c$

$c=p=\frac{M_{\mathrm{av}}}{t} \times \ln \left(\frac{H_{0}}{H_{t}}\right)$,

where $p$ is the production rate (i.e. $M$ or $D_{\mathrm{SON}}$; respectively), $c$ is the consumption rate (i.e. $C_{\mathrm{NH}_{4}}$ or $C_{\mathrm{FAA}}$, respectively), $M_{i}$ is the total content of the labelled pool, and $H_{i}$ is the excess ${ }^{15} \mathrm{~N}$ content of the labelled pool. Indices $i$ indicate initial (0), final $(t)$, and average (av) content.

In order to quantify the FAA mineralization rate $\left(M_{\mathrm{FAA}}\right.$; Fig. 1), the following equation were used (Watkins and Barraclough, 1996):

$M_{\mathrm{FAA}}=p \cdot \frac{a_{1}^{\prime} \cdot\left(M_{t} / M_{0}\right)^{\frac{p}{\theta}}-a_{0}^{\prime}}{a_{a a}^{\prime} \cdot\left(M_{t} / M_{0}\right)^{\frac{p}{\theta}}-a_{a a}^{\prime}}$,

with $p$ being the gross mineralization rate obtained from Eqs. (1) or (3) from the ${ }^{15} \mathrm{~N}-\mathrm{NH}_{4}^{+}$labelling experiment, extrapolated to $0-6 \mathrm{~h}$ by a logarithmic function; $\theta$ is $\left(M_{t}-M_{0}\right) / t$ with $M=\mathrm{NH}_{4}^{+}$content from the ${ }^{15} \mathrm{~N}-\mathrm{AA}$ labelling; $a_{a a}^{\prime}$ is the excess ${ }^{15} \mathrm{~N}$ fraction of the total FAAs pool averaged for the two time steps; and $a^{\prime}$ is the excess ${ }^{15} \mathrm{~N}$ fractions of the $\mathrm{NH}_{4}^{+}$pool from the ${ }^{15} \mathrm{~N}-\mathrm{AA}$ labelling.

\subsubsection{Iterative numerical model Ntrace}

Numerical ${ }^{15} \mathrm{~N}$ tracing models have been used to investigate soil inorganic N dynamics (Myrold and Tiedje, 1986; Rütting et al., 2011). Among the main advantages of a numerical approach is that process-specific gross $\mathrm{N}$ transformation rates are quantified simultaneously rather than sequentially (Rütting and Müller, 2007). Therefore, interactions between $\mathrm{N}$ transformations are accounted for. Here, we further developed the ${ }^{15} \mathrm{~N}$ tracing model Ntrace (Müller et al., 2007) to explicitly include FAA dynamics (Fig. 1). The mineralization of complex soil organic matter is represented as a two-step process: (1) peptide depolymerization releasing free AAs (FAA) (depolymerization rate $D_{\mathrm{SON}}$ ), and (2) the mineralization of FAA to $\mathrm{NH}_{4}^{+}$(amino acid mineralization rate $M_{\mathrm{FAA}}$ ). In addition, the mineralization of other (nonpeptide or non-AA polymers) $\mathrm{SON}\left(M_{\mathrm{SON}}\right)$ to $\mathrm{NH}_{4}^{+}$was included, which accounts for depolymerization followed by the mineralization of other $\mathrm{N}$ compounds (e.g. chitin; Bai et al., 2013). Gross $\mathrm{N}$ mineralization is, hence, the sum of $M_{\text {FAA }}$ and $M_{\text {SON }}$. Immobilization of FAAs ( $I_{\text {FAA }}$ ) and ammonium $\left(I_{\mathrm{NH}_{4}}\right)$ is also included in the model. In the current study, ${ }^{15} \mathrm{NO}_{3}^{-}$could not be measured even after the addition of ${ }^{15} \mathrm{NO}_{3}^{-}$, due to too low a $\mathrm{NO}_{3}^{-}$content of the soil. Therefore, oxidation and immobilization of $\mathrm{NH}_{4}^{+}$could not be separated and the quantified gross $\mathrm{NH}_{4}^{+}$immobilization $\left(I_{\mathrm{NH}_{4}}\right)$ is the sum of these two processes. The $\mathrm{N}$ transformations were either implemented as zero-order kinetics for large substrate pools that are constant in size during the incubation $\left(D_{\mathrm{SON}}\right.$ and $\left.M_{\mathrm{SON}}\right)$ or first-order kinetics for finite pools $\left(M_{\mathrm{FAA}}\right.$, $I_{\mathrm{FAA}}$, and $I_{\mathrm{NH}_{4}}$ ).
A Markov chain Monte Carlo sampling was used for parameter estimation by fitting the model to measured contents and ${ }^{15} \mathrm{~N}$ enrichments of the studied pools (Müller et al., 2007). The outcome is a probability density function for each model parameter, from which parameter averages and standard deviations can be calculated (Rütting and Müller, 2007). For $D_{\text {SON }}$ in the Podzol, the probability density function was truncated at zero. Therefore, the average and standard deviation for that parameter were calculated using functions for truncated normal distributions (Cohen Jr. and Woodward, 1953; Cicchinelli, 1965). For $\mathrm{N}$ transformations described by first-order kinetics, average gross rates were calculated by integrating the gross rates over the experimental period. A good fit of the model to the experimental data was achieved (Figs. 2 and 3).

A mix of 20 different amino acids was added to the soil. However, four of the added AAs (arginine, cysteine, glutamine, and histidine) could not be measured with the current methodology. The $\mathrm{N}$ of these four AAs accounted for $22 \%$ of the added ${ }^{15} \mathrm{~N}$ in the experiment. As those AAs also contribute to the mineralization $\left({ }^{15} \mathrm{~N}-\mathrm{NH}_{4}^{+}\right.$production), these were considered in the tracing model as follows: we assume that the soil pool of non-measured AAs has the same average ${ }^{15} \mathrm{~N}$ enrichment as the pool of the measurable 16 AAs. The pool of non-measured AAs was then included, having the same depolymerization, mineralization, and immobilization rates as the measured AAs. In order to evaluate the potential effect of the assumption of the same ${ }^{15} \mathrm{~N}$ enrichment, an uncertainty data analysis with altered ${ }^{15} \mathrm{~N}$ enrichment for the missing AAs was conducted, which indicated that altered ${ }^{15} \mathrm{~N}$ enrichment had only marginal effects on the estimated gross rates (see Supplement Table S1). We argue that the most realistic gross rates are quantified when including the non-measured AAs. However, in order to compare the results from the Ntrace with the analytical rates, $M_{\mathrm{FAA}}$ and $I_{\mathrm{FAA}}$ were additionally calculated for the measured AAs only, either for the entire incubation period (" $240 \mathrm{~h}$ ") or for the first $6 \mathrm{~h}$ only (same time frame as for analytical calculations). The gross rates including all AAs will be higher in proportion to the amount of AA-N (i.e. $22 \%$, when compared to rates for measurable AAs only).

\subsubsection{Nitrogen use efficiency}

Microbial $\mathrm{N}$ use efficiency of free amino acids (NUE) is the fraction of consumed FAAs that is not released as ammonium but incorporated into the microbial biomass (Mooshammer et al., 2014). We calculated NUE specifically for amino acids (NUE $\mathrm{FAA}_{\text {}}$ ) by another formula that is used by Mooshammer et al. (2014) and based on the Ntrace results:

$\mathrm{NUE}_{\mathrm{FAA}}=I_{\mathrm{FAA}} /\left(I_{\mathrm{FAA}}+M_{\mathrm{FAA}}\right)$. 


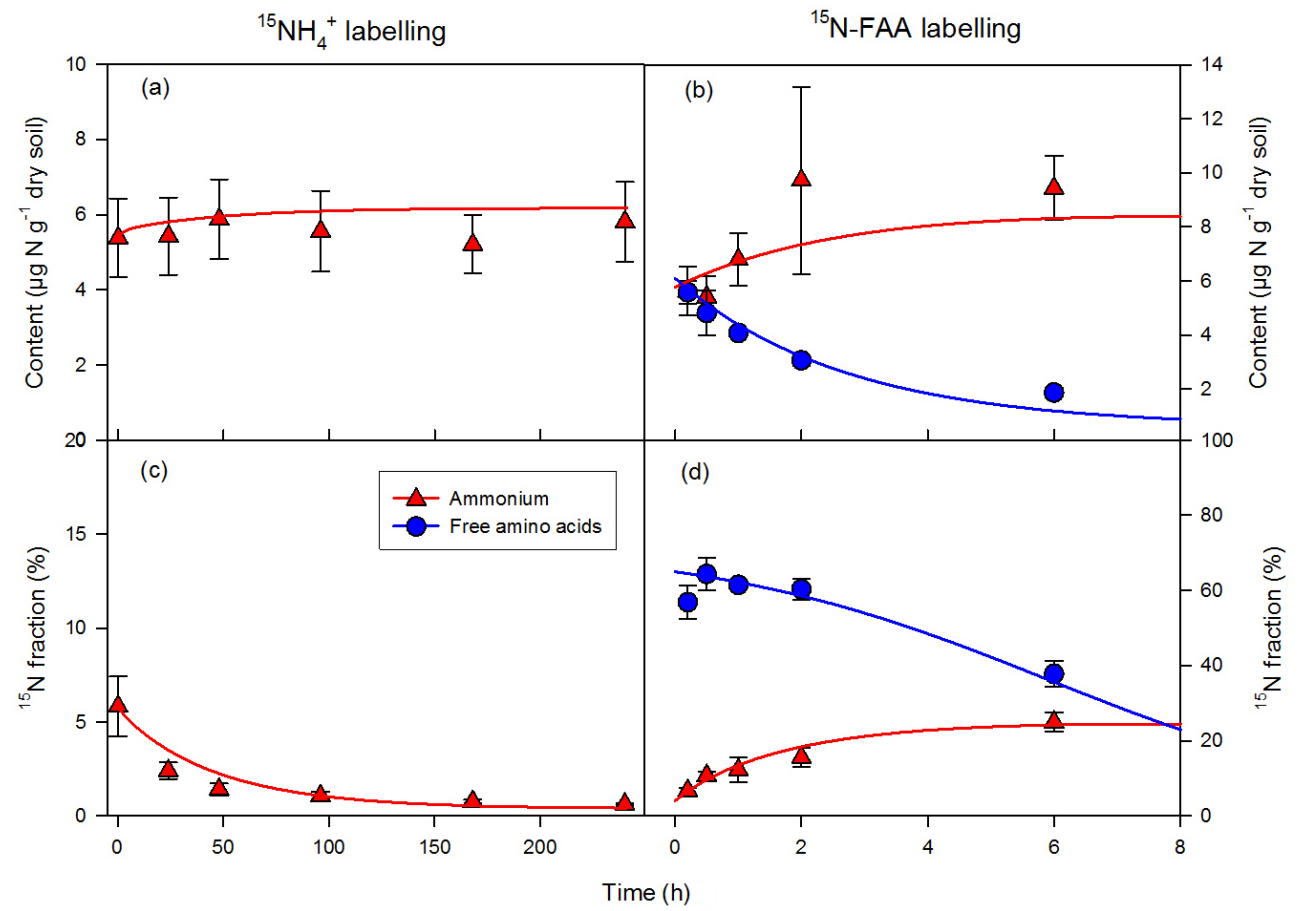

Figure 2. Umbrisol; time flow of the two labelling experiments: ${ }^{15} \mathrm{~N}-\mathrm{NH}+4$ labelling and ${ }^{15} \mathrm{~N}-\mathrm{FAA}$ labelling; symbols indicate data observation with standard deviation ( $n=5$; except ${ }^{15} \mathrm{~N}$ fraction of free amino acids: $n=4$ at 13 min), and lines indicate the two AA-pool model, where triangles and red is ammonium and circle and blue is FAAs. (a) and (b): $\mathrm{N}$ content $\left(\mu \mathrm{g} \mathrm{Ng}{ }^{-1} \mathrm{DW}\right.$ soil); (c) and (d): ${ }^{15} \mathrm{~N}$ fraction (\%).

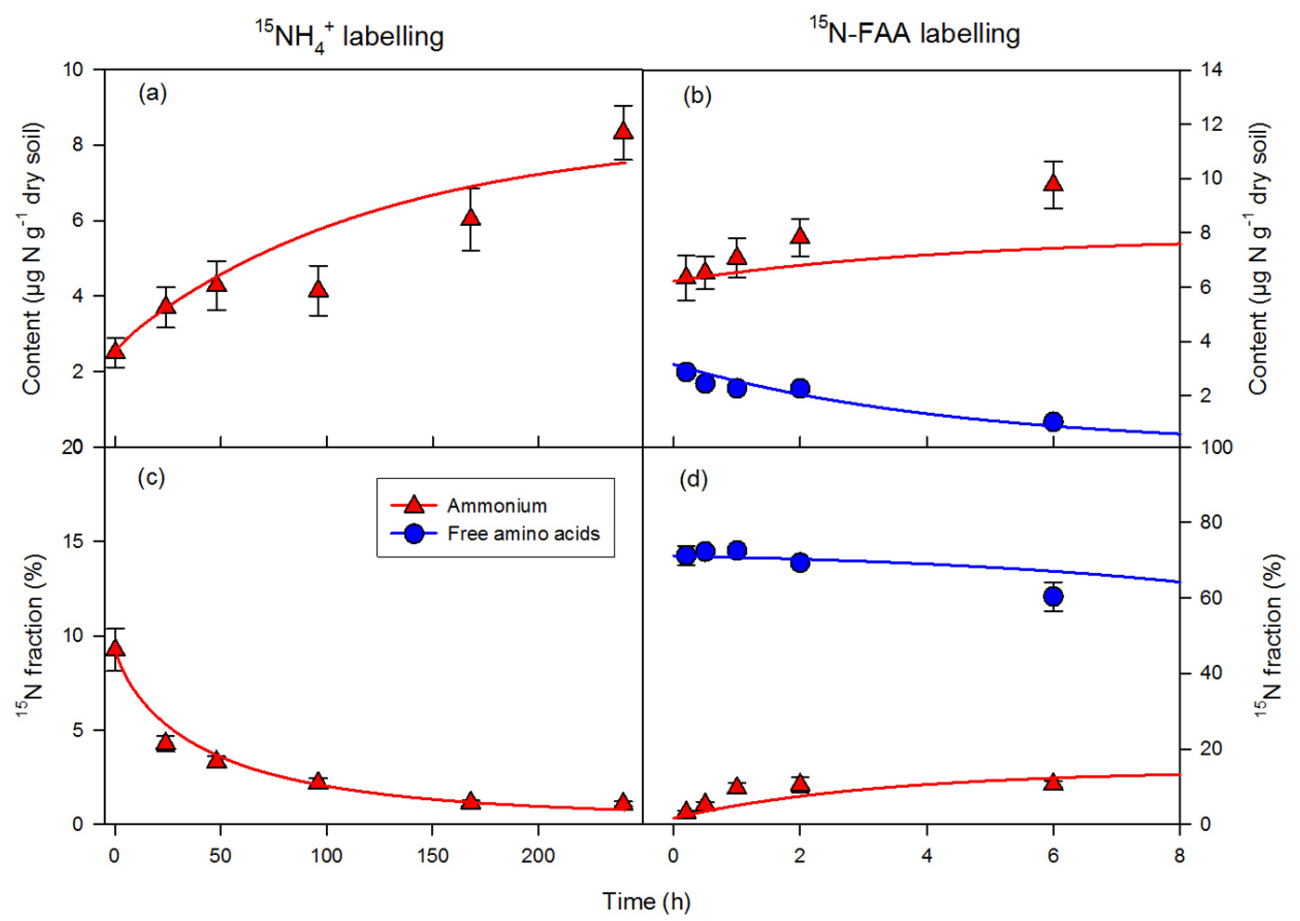

Figure 3. Podzol, time flow of the two labelling experiments: ${ }^{15} \mathrm{~N}-\mathrm{NH}_{4}^{+}$labelling and ${ }^{15} \mathrm{~N}-\mathrm{FAA}$ labelling; symbols indicate data observation with standard deviation ( $n=5$; except ${ }^{15} \mathrm{~N}$ fraction of free amino acids: $n=3$ at $13 \mathrm{~min}$ ), and lines indicate the two AA-pool model, where triangles and red is ammonium and circle and blue is FAAs. (a) and (b) $\mathrm{N}$ content $\left(\mu \mathrm{g} \mathrm{N} \mathrm{g}{ }^{-1} \mathrm{DW}\right.$ soil) and (c) and (d) ${ }^{15} \mathrm{~N}$ fraction $(\%)$. 
Table 1. Soil properties for the two soil types: Podzol and Umbrisol from Skogaryd. Averages with standard error. $\mathrm{pH}$ (in $1 \mathrm{M} \mathrm{KCl}$ ) gravimetric soil water content (GWC), soil organic matter (SOM), dry soil carbon $(\mathrm{C})$, nitrogen $(\mathrm{N}), \mathrm{C}-\mathrm{to}-\mathrm{N}$ ratio of soil, soil content of $\mathrm{NH}_{4}\left(\mu \mathrm{g} \mathrm{g}^{-1} \mathrm{DW}\right)$, and total free amino acid content (FAA in $\left.\mu \mathrm{g} \mathrm{Ng}^{-1} \mathrm{DW}\right)$.

\begin{tabular}{lll}
\hline & Podzol & Umbrisol \\
\hline $\mathrm{pH}$ & $3.7 \pm 0.0$ & $3.7 \pm 0.0$ \\
GWC $(\%)$ & $34.2 \pm 2.1$ & $52.9 \pm 3.8$ \\
SOM $(\%)$ & $6.9 \pm 0.4$ & $9.3 \pm 0.8$ \\
Dry soil C (\%) & $3.4 \pm 0.2$ & $4.7 \pm 0.5$ \\
Dry soil N (\%) & $0.15 \pm 0.01$ & $0.24 \pm 0.03$ \\
C-to-N ratio & $22.7 \pm 0.4$ & $19.4 \pm 0.3$ \\
$\mathrm{NH}_{4}\left(\mu \mathrm{g} \mathrm{g}^{-1} \mathrm{DW}\right)$ & $1.4 \pm 0.6$ & $1.1 \pm 0.9$ \\
FAA $\left(\mu \mathrm{g} \mathrm{N} \mathrm{g}^{-1} \mathrm{DW}\right)$ & $1.0 \pm 0.2$ & $0.4 \pm 0.1$ \\
\hline
\end{tabular}

\section{Results and discussion}

\subsection{Soil properties}

Both investigated soils were acidic, with a pH of 3.7, but differed in other properties (Table 1). The Umbrisol had higher $\mathrm{SOM}$ and total $\mathrm{C}$ and $\mathrm{N}$ content but a lower C-to-N ratio. Nitrate concentration was below the detection limit for both soils. Prior to the ${ }^{15} \mathrm{~N}$ addition, the Umbrisol had a 6 times higher FAA content compared to the Podzol, and the relative abundance of individual FAAs differed also between the two soils (Fig. 4). The FAA composition in the soil was initially dominated by acidic or non-aromatic compounds; possibly other FAAs may have been removed from the soil solution through plant root or microbe uptake (Andresen et al., 2011; Chen et al., 2015).

\subsection{Analytical versus numerical approaches for quantification of gross $\mathrm{N}$ rates}

Numerical tracing models represent robust methods to assess gross transformation rates, as all data points from the two isotope label experiments and all observed time steps are included. To our knowledge, the quantification of total gross FAA mineralization and peptide depolymerization rates has not been done by numerical tracing models. A particular weakness of analytical approaches is that substrate addition stimulates consumption processes (Schimel, 1996; Di et al., 2000), which is also true for FAAs. This problem can be minimized by using numerical tracing models as the stimulation will be greatest immediately after ${ }^{15} \mathrm{~N}$ labelling, but numerical models allow the integration of transformation rates over a much longer period (Rütting et al., 2011). We did indeed find that the numerically derived gross rates for $M_{\text {FAA }}$ and $I_{\text {FAA }}$ when integrated over $6 \mathrm{~h}$, were several fold higher than rates integrated over the entire experimental duration $(240 \mathrm{~h}$; Table 2; Fig. 5). Differences between gross rates derived from analytical and numerical models were greatest for FAA

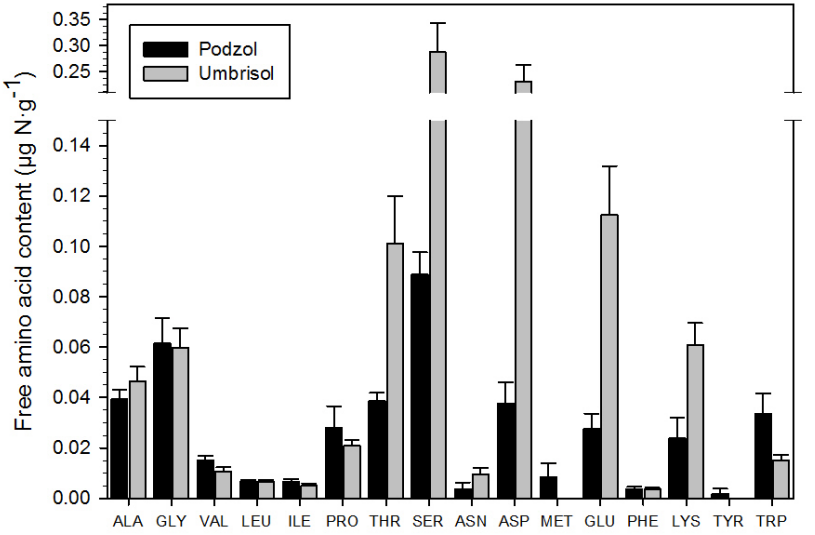

Figure 4. Initial soil content of individual amino acids ( $\mu \mathrm{g} N-$ FAA g $^{-1}$ DW soil) indicated as average $\pm \mathrm{SE}$ (standard error) $(n=$ $5)$.

consumption, while smaller differences were found for $D_{\text {SON }}$ and total mineralization (Table 2; Fig. 5). This points to an overstimulation of the processes by the addition of FAAs and demonstrates the advantage of a longer incubation time with numerical data analysis to achieve more realistic gross rates.

In the Podzol we observed both FAA mineralization $\left(M_{\mathrm{FAA}}\right)$ as well as the mineralization of other SON $\left(M_{\text {SON }}\right)$. The total gross $\mathrm{N}$ mineralization rate $\left(M_{\mathrm{FAA}}+M_{\mathrm{SON}}\right)$ derived from Ntrace integrated over $240 \mathrm{~h}$ was lower but comparable to the analytically determined gross mineralization $(M)$ rate (Table 2; Fig. 5). In this soil, FAA mineralization contributed by only 12 to $15 \%$ to total gross $\mathrm{N}$ mineralization. For the Umbrisol, gross mineralization from Ntrace was only half the gross rate estimated by the analytical model and entirely assigned to $M_{\mathrm{FAA}}$. The analytical model does not distinguish between mineralization from FAA or other $\mathrm{N}$ forms $\left(M_{\mathrm{FAA}}\right.$ or $\left.M_{\mathrm{SON}}\right)$ but provides one total rate $(M)$. The quantification of FAA mineralization is possible using the analytical Eq. (4) but requires an ${ }^{15} \mathrm{~N}$ tracing approach and two ${ }^{15} \mathrm{~N}$ labellings (FAA and $\mathrm{NH}_{4}^{+}$).

For Podzol, depolymerization rates $\left(D_{\mathrm{SON}}\right)$ quantified by Ntrace were smaller compared to the analytical results, while for Umbrisol the rates quantified with Ntrace and the analytical equation were similar (Table 2; Fig. 5). Gross depolymerization quantified by the analytical approach only had a minor decrease with increasing incubation time (Table 2; Fig. $5 \mathrm{c}$ and d), suggesting no or only little remobilization of ${ }^{15} \mathrm{~N}$ (Bjarnason, 1988). The similarity of $D_{\mathrm{SON}}$ rates quantified with Ntrace and by the analytical approach confirms the validity of the numerical tracing model. The main difference between the two approaches is that the numerical approach estimates the rate for the entire $240 \mathrm{~h}$ of incubation, while the analytical approach considers a limited time span of $6 \mathrm{~h}$ maximum. 
Table 2. $\mathrm{N}$ dynamics rates from analytical equations (Eqs. 1-4 and 6) and Ntrace numerical model; average in $\mathrm{ng} \mathrm{Ng}^{-1} \mathrm{~h}^{-1}$ and standard deviation; NUE FAA is dimensionless. Peptide depolymerization rate $\left(D_{\mathrm{SON}}\right)$; FAA immobilization rate $\left(I_{\mathrm{FAA}}\right)$; FAA mineralization rate $\left(M_{\mathrm{FAA}}\right)$; amino acid consumption $\left(C_{\mathrm{FAA}}\right)$; mineralization rate of organic $\mathrm{N}\left(M_{\mathrm{SON}}\right)$; gross $\mathrm{N}$ mineralization $(M)$; ammonium consumption $\left(C_{\mathrm{NH}_{4}}\right)$; immobilization rate of $\mathrm{NH}_{4}^{+}\left(I_{\mathrm{NH}_{4}}\right)$; and microbial amino acid nutrient use efficiency (NUE $\left.\mathrm{FAA}\right)$ (Eq. 5). For $D_{\mathrm{SON}}, C_{\mathrm{FAA}}$, and $\mathrm{NUE}_{\mathrm{FAA}}$, the time step 30 to $360 \mathrm{~min}$ is presented; $M_{\mathrm{FAA}}$ and $I_{\mathrm{FAA}}$ for all $20 \mathrm{AAs}$ over $240 \mathrm{~h}$. $C_{\mathrm{FAA}}$ and $M$ from Ntrace are calculated sums $\left(M=M_{\mathrm{SON}}+M_{\mathrm{FAA}}\right.$ and $\left.C_{\mathrm{FAA}}=I_{\mathrm{FAA}}+M_{\mathrm{FAA}}\right)$.

\begin{tabular}{llllll}
\hline & \multicolumn{2}{c}{ Podzol } & & \multicolumn{2}{c}{ Umbrisol } \\
\cline { 2 - 3 } \cline { 5 - 6 } \cline { 5 - 6 } & Analytical & Ntrace & & Analytical & Ntrace \\
\hline$D_{\text {SON }}$ & $58.8(53.2)$ & $18.2(12.6)$ & & $316.6(151.3)$ & $288.5(40.6)$ \\
$I_{\text {FAA }}$ & - & $16.8(1.4)$ & & - & $172.3(18.2)$ \\
$M_{\text {FAA }}$ & - & $11.2(1.4)$ & & - & $131.7(12.6)$ \\
$C_{\text {FAA }}$ & $313.8(40.6)$ & $28.0(2.8)$ & & $851.6(191.9)$ & $303.9(30.8)$ \\
$M_{\mathrm{SON}}$ & - & $61.6(5.6)$ & & - & 0.0 \\
$M$ & $100.8(35.0)$ & $72.8(7.0)$ & & $239.5(135.9)$ & $131.7(12.6)$ \\
$C_{\mathrm{NH}_{4}}\left(I_{\mathrm{NH}_{4}}\right)$ & $50.4(11.2)$ & $57.4(5.6)$ & & $166.7(198.9)$ & $128.9(19.6)$ \\
$\mathrm{NUE}_{\mathrm{FAA}}$ & - & $0.60(0.12)$ & & - & $0.57(0.12)$ \\
\hline
\end{tabular}
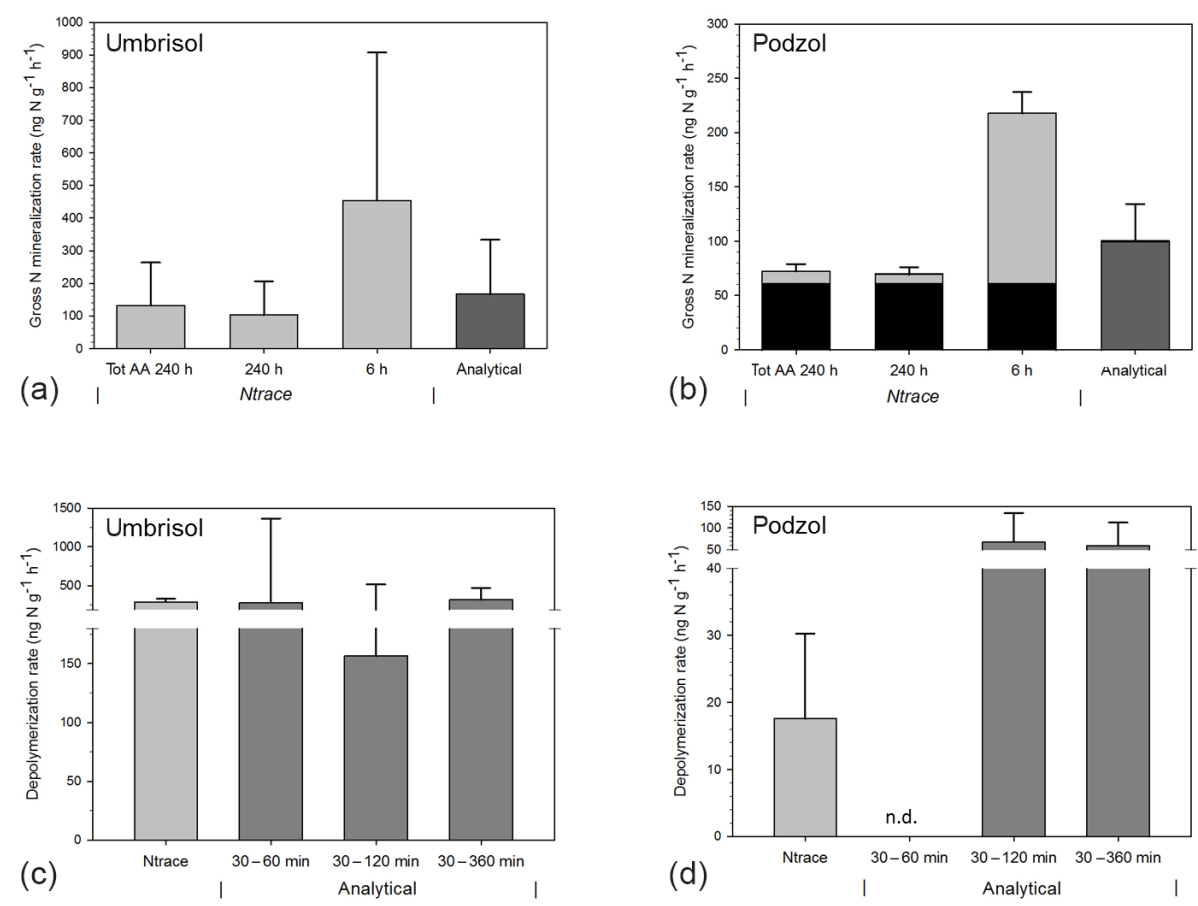

Figure 5. $\mathrm{N}$ transformation rates obtained by numerical modelling (Ntrace) and analytical equations. Gross $\mathrm{N}$ mineralization rates $\left(\mathrm{ng} \mathrm{N} \mathrm{g}{ }^{-1} \mathrm{~h}^{-1}\right)$ indicated as average with deviation $(n=5)$ for Umbrisol (a) and Podzol (b); from the Ntrace model as sum of $M_{\mathrm{SON}}$

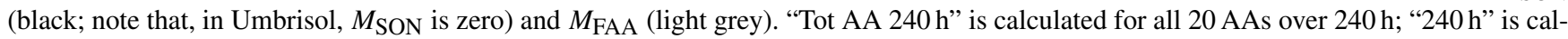
culated for the 16 measurable AAs over $240 \mathrm{~h}$, and " $6 \mathrm{~h}$ " is calculated for the 16 measurable AAs for the initial $6 \mathrm{~h}$. "Analytical" (dark grey): from the analytical equation for the time step 0 to $24 \mathrm{~h}$. Depolymerization rate (total) in $\mathrm{ng} \mathrm{N} \mathrm{g}^{-1} \mathrm{~h}^{-1}$ as average with standard deviation $(n=5)$, for Umbrisol (c) and Podzol (d) from Ntrace model or at the time steps "30-60 min" (for Podzol this is not determined (n.d.) due to unchanged ${ }^{15} \mathrm{~N}$ in all replicates), "30-120 min", and "30-360 min" from the analytical equation.

\section{Gross $\mathbf{N}$ dynamics in two contrasting forest soils}

As the numerical Ntrace model is less prone to disturbance by ${ }^{15} \mathrm{~N}$ label addition and as interactions between different $\mathrm{N}$ transformations are taken into account, we suggest that this approach provides more realistic gross $\mathrm{N}$ transformation rates. The ratio of total gross $\mathrm{N}$ mineralization $(M)$ to the peptide depolymerization $\left(D_{\mathrm{SON}}\right)$ rate ranges from 5 to $25 \%$ in both organic soils and plant litter, based on analytical calculations (Wanek et al., 2010; Wild et al., 2015). We 
found a much higher ratio in both soils ( $76 \%$ for Umbrisol and $170 \%$ for Podzol) using the analytical approach, while Ntrace resulted in $M$-to- $D_{\text {SON }}$ ratios of 46 and $400 \%$, respectively. Thus, gross $\mathrm{N}$ mineralization was highly important for the $\mathrm{N}$ cycle and for making $\mathrm{N}$ available in the soil. Moreover, the $M_{\mathrm{FAA}}$ amounted to $46 \%$ (Umbrisol) and $65 \%$ (Podzol) of $D_{\text {SON }}$ (Table 2; Ntrace Fig. 5). The finding of $\sim 50 \%$ of depolymerized peptide $\mathrm{N}$ being further mineralized to $\mathrm{NH}_{4}^{+}$as well as the higher total mineralization than peptide depolymerization in the Podzol suggest that peptide depolymerization is not the single major rate-limiting step for the soil N cycle (Schimel and Bennett, 2004). Rather, the results suggest that the amino acid mineralization rate is a major part of the gross $\mathrm{N}$ mineralization as hypothesized and can be considered as a co-limiting step for plant $\mathrm{N}$ availability in terrestrial ecosystems.

The Podzol was characterized by a lower peptide depolymerization rate compared to previously studied sub- and topsoils from forests and grasslands (Wild et al., 2015). The Umbrisol soil, being more N, SOM, and FAA rich (Table 1), showed consistently higher gross $\mathrm{N}$ transformation rates (Table 2; Fig. 5). This agrees with the finding of a correlation of high $\mathrm{N}$ status and faster $\mathrm{N}$ cycling (organic and inorganic) across cold temperate forests (Finzi and Berthrong, 2005). One pronounced difference between the two soils was the mineralization dynamics: for the Umbrisol the gross $\mathrm{N}$ mineralization was estimated as entirely derived from the FAA pool ( $100 \% M_{\text {FAA }}$ ), while in the Podzol, $M_{\text {FAA }}$ contributed only by $15 \%$ to the total gross $\mathrm{N}$ mineralization (Fig. 5). Consequently, the Umbrisol strongly depended on FAAs as source for IN, while in the Podzol the mineralization of other organic $\mathrm{N}$ forms $\left(M_{\mathrm{SON}}\right)$ dominated the IN production. Notably, $M_{\text {FAA }}$ was about 10-fold lower in Podzol compared to Umbrisol. This can be explained by the much smaller $D_{\mathrm{SON}}$ in the Podzol (Fig. 5), limiting the substrate for $M_{\mathrm{FAA}}$ in this soil, which is also reflected in the 6-fold smaller FAA content (Table 1). Variation in the contribution of $M_{\mathrm{FAA}}$ to $M$ has been reviewed previously, ranging from 35 to $100 \%$ across agricultural and natural soils, from results obtained using analytical calculations (Andresen et al., 2015). The C-to-N ratio for the two soils near 20, which indicates that the soils are at a tipping point for either $\mathrm{C}$ or $\mathrm{N}$ limitation, according to the concept from Mooshammer at al. (2014; Fig. 1). Our result of amino acid nutrient use efficiency (NUEFAA) was 0.57 for Umbrisol and 0.60 for Podzol, which points towards a carbon limitation in those soils, as we hypothesized.

\section{Suggested improvements of the laboratory method}

The FAA label addition was 10 to 20 times larger than the initial FAA content in the soil. Wanek et al. (2010) recommend adding a maximum of $25 \%$ of the background amino acid content, but we were not able to reach the rec- ommended level. This specification requires pre-knowledge of the FAA content in the soils. The addition of FAAs might cause an unintended "hot-spot" effect (Kuzyakov and Blagodatskaya 2015), which stimulates depolymerization by priming (Schimel, 1996; Di et al., 2000). Furthermore, upon addition of a high amount of amino acids, peptidases could be repressed (Vranova et al., 2013; Glenn et al., 1973). Therefore, future studies should apply lower amounts of FAA.

Adsorption (physical and chemical) of the added label to SOM cannot be evaluated with our methodology, even when comparing initial FAA, added FAAs, and the FAA amount after $10 \mathrm{~min}$ time step (data not shown) because significant microbial $\mathrm{N}$ transformations cannot be excluded (Jones et al., 2013). However, during the first time steps (30, 60, and $120 \mathrm{~min}$ ) only little change in ${ }^{15} \mathrm{~N} \%$ fraction was observed (Figs. 2 and 3), suggesting quite small depolymerization. This points to the fact that there can be a limit to how small a peptide depolymerization rate we can measure with the current methodology. The individual FAAs were consumed equally through the time series as suggested by decreases in content (data not shown), and at the final time step, the individual FAA contents were back at the background level; hence, our procedure encompasses a life cycle for the added FAA quantity.

We did not assess peptide depolymerization rates for individual FAAs because transformations between FAAs (Knowles et al., 2010) can neither be ruled out nor tested with our experimental set-up (e.g. potential aspartic acid formation from asparagine or break down of larger FAAs such as lysine to a smaller size such as serine). We aimed at quantifying gross rates relevant for organic $\mathrm{N}$ transformations in soils, using incubations with either an ${ }^{15} \mathrm{~N}-\mathrm{NH}_{4}^{+}$or ${ }^{15} \mathrm{~N}-\mathrm{AA}$ mix label. Only the first sampling time point was synchronized for the two incubation types; we suggest that at least one more synchronized sampling should be done in future experiments. Furthermore, after the addition of ${ }^{15} \mathrm{~N}$-labelled FAA, we observed an ${ }^{15} \mathrm{~N}$ enrichment of $\mathrm{NH}_{4}^{+}$even at the last extraction (Figs. 2 and 3). Therefore, future studies should include later extractions (e.g. at $48 \mathrm{~h}$ ) to follow the fate of the added ${ }^{15} \mathrm{~N}-\mathrm{AA}$. We expect that these suggestions would further improve the model estimation.

Finally, a further improved understanding of the FAA dynamics can be achieved by improving the analytical capacity for measuring all 20 proteinogenic FAAs. In this experiment we could not measure four of the added amino acids, but they were considered in Ntrace for realistic quantification of, especially, $M_{\mathrm{FAA}}$. Assumptions had to be made for the ${ }^{15} \mathrm{~N}$ enrichment of the non-measured FAAs and that the nonmeasured FAA concentration decreased like the measured FAAs. The quantified gross rates were not very sensitive to the alteration of the ${ }^{15} \mathrm{~N}$ enrichment of the non-measured FAAs (see Table S1). We assumed a similar behaviour as all 16 measured FAAs showed similar time courses in soil content after labelling (data not shown). 
An even further development of the numerical model would include the $\mathrm{NO}_{3}^{-}$dynamics in a soil with that property. Another outlook is that depolymerization rates of polymers other than amino acids (such as amino sugar polymers) are potentially an important part of the total depolymerization. Hence, further research is needed to uncover the importance of other limiting steps in the $\mathrm{N}$ cycle.

Concluding, we suggest that (i) numerical modelling in conjunction with ${ }^{15} \mathrm{~N}$ tracing is an improvement for simultaneously determining FAA mineralization, peptide depolymerization, and gross $\mathrm{N}$ mineralization rates compared to the analytical equations which only determine one rate using data from only two time points; (ii) FAA mineralization and FAA immobilization rates can be used for assessing FAA use efficiency ( $\mathrm{NUE}_{\mathrm{FAA}}$ ) and soil $\mathrm{N}$ limitation; (iii) FAA mineralization might be as important a rate-limiting step for gross $\mathrm{N}$ mineralization as the peptide depolymerization rate is because about half of all depolymerized peptide $\mathrm{N}$ is consecutively mineralized; and (iv) the depolymerization of other components in the soil is an additional potentially rate-limiting step for the $\mathrm{N}$ cycle, which needs further investigation.

\section{The Supplement related to this article is available online at doi:10.5194/soil-2-433-2016-supplement.}

Author contributions. Tobias Rütting, Leif Klemedtsson, Pascal Boeckx, and Louise C. Andresen planned the experiments; Anna-Karin Björsne and Louise C. Andresen conducted the field work and lab incubations, supervised by Tobias Rütting. Samuel Bodé conducted the stable isotope analysis. Tobias Rütting developed the Ntrace model. All authors discussed the conceptual model and contributed to data interpretation and the writing of the paper.

Acknowledgements. Stijn Vandevoorde and Katja van Nieuland from ISOFYS are thanked for the analysis of amino acids, inorganic nitrogen, and soils. The project was financially supported by the Swedish Research Council Formas and the Swedish strategic research area "Biodiversity and Ecosystem services in a Changing Climate - BECC" (http://www.becc.lu.se/). Skogaryd Research Catchment is part of SITES (Swedish Infrastructure for Ecosystem Studies, http://www.fieldsites.se).

Edited by: S. Grandy

Reviewed by: three anonymous referees

\section{References}

Andresen, L. C., Michelsen, A., Jonasson, S., and Ström, L. Seasonal changes in nitrogen availability, and root and microbial uptake of ${ }^{15} \mathrm{~N}^{13} \mathrm{C}_{9}$-phenylalanine and ${ }^{15} \mathrm{~N}$-ammonium in situ at a temperate heath, Appl. Soil Ecol., 5, 94-101, 2011.

Andresen, L. C., Bode, S., Tietema, A., Boeckx, P., and Rütting, T.: Amino acid and $\mathrm{N}$ mineralization dynamics in heathland soil after long-term warming and repetitive drought, SOIL, 1, 341349, doi:10.5194/soil-1-341-2015, 2015.

Bai, Z., Bodé, S., Huygens,D., Zhang, X., and Boeckx, P.: Kinetics of amino sugar formation from organic residues of different quality, Soil Biol. Biochem., 57, 814-821, 2013.

Bardgett, R. D., Streeter, T. C., and Bol, R.: Soil microbes compete effectively with plants for organic-nitrogen inputs to temperate grasslands, Ecology, 84, 1277-1287, 2003.

Bjarnason, S.: Calculation of gross nitrogen immobilization and mineralization in soil, J. Soil Sci., 39, 393-406, 1988.

Chen, J., Zelikova, T. J., Pendall, E., Morgan, J. A., and Williams, D. G.: Daily and seasonal changes in soil amino acid composition in a semiarid grassland exposed to elevated $\mathrm{CO}_{2}$ and warming, Biogeochemistry, 123, 135-146, 2015.

Cicchinelli, A. L.: Tables of Pearson-Lee-Fisher functions of singly truncated normal distributions, Biometrics, 21, 219-226, 1965.

Cohen Jr., A. C. and Woodward, J.: Tables of Pearson-Lee-Fisher Functions of Singly Truncated Normal Distributions, Biometrics, 9, 489-497, 1953.

Di, H. J., Cameron, K. C., and McLaren, R. G.: Isotopic dilution methods to determine the gross transformation rates of nitrogen, phosphorus, and sulfur in soil: a review of the theory, methodologies, and limitations, Aust. J. Soil Res., 38, 213-230, 2000.

Ernfors, M., Rütting, T., and Klemedtsson, L. Increased nitrous oxide emissions from a drained organic forest soil after exclusion of ectomycorrhizal mycelia, Plant Soil, 343, 161-170, 2011.

Finzi, A. C. F. and Berthrong, S. T. B.: The uptake of amino acids by microbes and trees in three cold-temperate forests, Ecology, 86, 3345-3353, 2005.

Glenn, A. R., Both, G. W., McInnes, J. L., May, B. K., and Elliott, W. H.: Dynamic State of the Messenger RNA Pool Specific for Extracellular Protease in Bacillus amyloliquefaciens: Its Relevance to the Mechanism of Enzyme Secretion, J. Mol. Biol., 73, 221-230, 1973.

Houlton, B. Z. and Morford, S. L.: A new synthesis for terrestrial nitrogen inputs, SOIL, 1, 381-397, doi:10.5194/soil-1-381-2015, 2015.

Husek, P.: Amino acid derivatization and analysis in five minutes, FEBS Lett., 280, 354-356, 1991.

Jones, D. L., Clode, P. L., Kilburn, M. R., Stockdale, E. A., and Murphy, D. V.: Competition between plant and bacterial cells at the microscale regulates the dynamics of nitrogen acquisition in wheat (Triticum aestivum), New Phytol., 200, 796-807, 2013.

Kirkham, D. and Bartholomew, W.: Equations for following nutrient transformations in soil, utilizing tracer data, Soil Sci. Soc. Am. Proc., 18, 33-34, 1954.

Knowles, T. D. J., Chadwick, D. R., Bol, R., and Evershed, R. P.: Tracing the rate and extent of $\mathrm{N}$ and $\mathrm{C}$ flow from ${ }^{13} \mathrm{C},{ }^{15} \mathrm{~N}$ glycine and glutamate into individual de novo synthesised soil amino acids, Org. Geochem., 41, 1259-1268, 2010. 
Kuzyakov, Y. and Blagodatskaya, E.: Microbial hotspots and hot moments in soil: Concept \& review, Soil Biol. Biochem., 83, 184-199, 2015.

Mooshammer, M., Wanek, W., Hämmerle, I., Fuchslueger, L., Hofhansl, F., Knoltsch, A., Schnecker, J., Takriti, M., Watzka, M., Wild, B., Keiblinger, K. M., Zechmeister-Boltenstern, S., and Richter, A.: Adjustment of microbial nitrogen use efficiency to carbon : nitrogen imbalances regulates soil nitrogen cycling, Nat. Commun., 5, 3694, doi:10.1038/ncomms4694, 2014.

Müller, C., Rütting, T., Kattge, J., Laughlin, R. J., and Stevens, R. J.: Estimation of parameters in complex ${ }^{15} \mathrm{~N}$ tracing models by Monte Carlo sampling, Soil Biol. Biochem., 39, 715-726, 2007.

Myrold, D. D. and Tiedje, J. M.: Simultaneous estimation of several nitrogen-cycle rates using ${ }^{15} \mathrm{~N}$ : theory and application, Soil Biol. Biochem., 18, 559-568, 1986.

Påhlsson, L.: Ed. Vegetationstyper i Norden, TemaNord, Nordisk ministerråd, Copenhagen, 510 pp., 1998.

Robertson, G. P. and Groffman, P. M.: Nitrogen transformations, in: Cpt. 14, Soil microbiology, ecology, and biochemistry, edited by: Paul, E. A., 4th Edn., Academic Press, Elsevier, Oxford, 2015.

Rütting, T. and Müller, C.: ${ }^{15} \mathrm{~N}$ tracing models with a Monte Carlo optimization procedure provide new insights on gross $\mathrm{N}$ transformations in soils, Soil Biol. Biochem., 39, 2351-2361, 2007.

Rütting, T., Huygens, D., Staelens, J., Müller, C., and Boeckx, P.: Advances in ${ }^{15} \mathrm{~N}$-tracing experiments: new labelling and data analysis approaches, Biochem. Soc. Trans., 39, 279-283, 2011.
Schimel, J. P.: Assumptions and errors in the ${ }^{15} \mathrm{NH}_{4}^{+}$pool dilution technique for measuring mineralization and immobilization, Soil Biol. Biochem., 28, 827-828, 1996.

Schimel, J. P. and Bennett, J.: Nitrogen mineralization: challenges of a changing paradigm, Ecology, 85, 591-602, 2004.

Schimel, J. P. and Chapin III, F. S.: Tundra plant uptake of amino acid and $\mathrm{NH}_{4}^{+}$nitrogen in situ: plants compete well for amino acid N, Ecology, 77, 2142-2147, 1996.

Stevens, R. J. and Laughlin, R. J.: Determining N-15 in nitrite or nitrate by producing nitrous-oxide, Soil Sci. Soc. Am. J., 58, 11081116, 1994.

Vranova, V., Rejsek, K., and Formanek, P.: Proteolytic activity in soil: A review, Appl. Soil Ecol., 70, 23-32, 2013.

Wanek, W., Mooshammer, M., Blochl, A., Hanreich, A., and Richter, A.: Determination of gross rates of amino acid production and immobilization in decomposing leaf litter by a novel $\mathrm{N}-15$ isotope pool dilution technique, Soil Biol. Biochem., 42, 1293-1302, 2010.

Watkins, N. and Barraclough, D.: Gross rates of N mineralization associated with the decomposition of plant residues, Soil Biol. Biochem., 28, 169-175, 1996.

Wild, B., Schnecker, J., Knoltsch, A., Takriti, M., Mooshammer, M., Gentsch, N., Mikutta, R., Alves, R. J. E., Gittel, A., Lashchinskiy, N., and Richter, A.: Microbial nitrogen dynamics in organic and mineral soil horizons along a latitudinal transect in western Siberia, Global Biogeochem. Cy., 29, 567-582, 2015. 